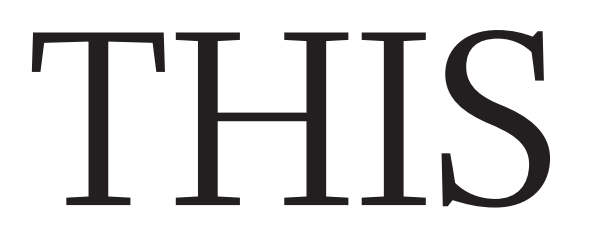

EDITORIALS
FUTURES 400 and counting for Nature's science-fiction column $\mathbf{p . 6}$

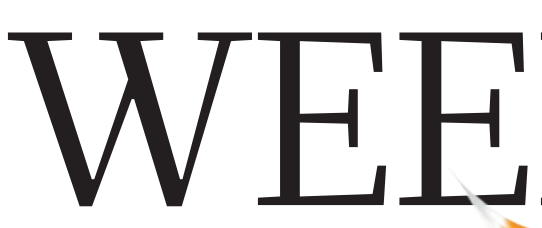

WORLD VIEW The problem with consensus reports is the consensus $\mathbf{p . 7}$
GOLDFISH Sent

sideways by sensor startling sounds p.9

\title{
High-interest clones
}

\section{Research into cloned human cells has left the spectre of past scientific fraud behind. But reaction to the earlier work still holds worthwhile lessons.}

$\mathrm{W}$ hen, in 2004, Woo Suk Hwang claimed to have produced a stem-cell line derived from an embryonic human clone, his research, done at Seoul University, sparked intense interest and hype. Even though Hwang's work later proved to be fraudulent, all advances in the field risk being measured against it. At the same time, researchers seek to distance themselves from the episode to the extent that its ethical implications for current work are rarely discussed.

This week, scientists have come the closest of any so far in emulating Hwang's claimed results: on page 70, researchers from the New York Stem Cell Foundation Laboratory report using cloning technology to reprogram human DNA taken from an adult and create embryonic stem cells. But they do not use the term cloning to describe their results. That is one of many contrasts between the research landscape now and in 2004.

Hwang's claims received worldwide attention. Patient groups jumped for joy; scientists around the world used the results to gather more funds for stem-cell research; and bioethicists emerged to justify or condemn the work. Reaction this week is likely to be more muted.

Discussion of the ethical concerns raised by such work have calmed, and the research group behind the latest study dealt with one of the most divisive issues - the retrieval of human eggs from donors in a transparent and considered way. Hwang, by contrast, had procured eggs unethically and illegally, a problem first brought to public attention in Nature (see Nature 429, 3; 2004). Whereas discussion of Hwang's results featured the phrase 'therapeutic cloning' and so invited (sometimes wilful) confusion with reproductive cloning and the spectre of technology misuse, the latest paper refers only to the reprogramming of cells to a pluripotent state. A final issue - that embryos are destroyed in the process of the research - does still apply.

The ultimate goal of such research is to create patient-specific stem cells for drug screening and the growth of genetically identical tissue for transplantation. Yet cloning, whether called that or not, is no longer the only means to this end, as it seemed in Hwang's time. Induced pluripotent stem (iPS) cells, first developed in 2006, now offer the same promise without the need for egg recruitment or embryo destruction: they are produced from adult cells by introducing a few genetic factors to the cell rather than using an entire egg. When therapeutic-cloning studies stalled on an egg shortage, iPS cell frenzy filled the gap. Competition between the approaches is fierce, and the authors of the current study point out the many weaknesses of iPS cells to bolster their own work. But their approach, too, has a long way to go.

The biggest reason that the results won't generate Hwang-like headlines is that they do not go as far. Hwang claimed to have created a cloned human embryo with the same 46 chromosomes as its parent, in a very similar way to how scientists have produced living cloned mammals. Hwang's embryo would have been viable, generating huge ethical debate. His claimed results were so advanced that in 2005 , Hwang was applying to start clinical trials.

The cells presented this week have an 23 extra chromosomes from the egg. Hwang, like most researchers in the field, removed this DNA and used the egg merely to drive reprogramming; it didn't work. The latest study left the egg DNA in, and says that some element of it is essential.

The cells derived from this 'triploid' embryo show many of the functions of normal cells, but such embryos are not viable and it is

"Even though Hwang's work proved to be fraudulent, all advances in the field risk being measured against it." not yet clear how triploid cells would mimic the behaviour of cells in tissue. No one will be calling them clinically relevant any time soon.

Still, iPS cell work is on the defensive, and this study provides proof that human somatic cells can be reprogrammed.

Now, researchers have to prove that the work is a step towards a biomedically useful stem-cell line. The authors are confident that they can produce a stem-cell line from a 'normal' diploid cloned embryo, as Hwang claimed to do. They will have to work out what it is in the egg's genetic material that is necessary for the reprogramming.

The latest achievement points in the same direction as Hwang's claims. If researchers were to find the magic element in the egg, not only would there again be excitement, but the old ethical issues would resurface. Hype around potential procedures would increase the market for eggs, which is perhaps hard to justify. The embryos would be viable, no doubt again producing fears of self-cloning dictators. (For that reason, this might be a good time for the United Nations to hammer out cloning regulations or restrictions, which have been hamstrung by political and religious debate.) And desperate patients would find doctors ready to give them unproven and unsafe embryonic-stem-cell treatments.

The results might look mundane. But the potential for reasoned excitement and irrational hype remain.

\section{The games begin}

\section{Frustrations of the newest European member states will shape debate over research funding.}

$\mathrm{W}$ ith some $€ 80$ billion (US $\$ 105$ billion) to distribute, the next European research funding programme will have one of the world's most generous science budgets. The European Commission has promised radical change to the programme, called Horizon 2020, and researchers, politicians and commentators have been waiting to see the results. This week, Nature reveals the programme's new look.

A leaked draft of the commission's plans for Horizon 2020, 